\title{
COMMON CAUSES OF LEAKAGES IN PARAPET ROOF CONSTRUCTION IN GHANA: A CASE STUDY FROM KUMASI
}

\author{
S.O. Afram \\ Department of Architecture, \\ Kwame Nkrumah University of Science and Technology, Kumasi, Ghana
}

\begin{abstract}
In Ghana, especially Kumasi, the second largest city after Accra, the country's capital, parapet roof construction became fashionable in building construction in the 1970's. It entailed hiding the roofs of buildings from view behind parapet walls. This concept is popularly known as "Bohyemu", literally meaning "construct it inside"” or more appropriately "hide it in". The paper examines roof designs and their functional requirements in general and specifically discusses problems associated with parapet roof construction in the country, with particular reference to Kumasi. It outlines some examples of such roofing and their respective problem areas, which include design and poor detailing, and offers practical suggestions that may help in arresting these problems. The paper concludes by sounding a note of caution to technocrats in the building profession to be more diligent in the detailing, construction and supervision of this type of roof, as well as "diagnosing" problems of leakages associated with parapet roofs, since they are usually caused by a plethora of factors which, if not well-considered and assessed, may ultimately lead to the wrong "prescriptions" in trying to in solve them.
\end{abstract}

Keywords: Parapet, Roof Design, Roof Leakage, Construction

\section{INTRODUCTION}

It is known the world over that a roof is that component of a building which is most associated with the concept of shelter. A homeless person is usually described as someone without a "roof over his or her head". It is the part of the external envelope which spans the external walls of a building at their highest level and being part of the envelope, must fulfil the functions required of the same, i.e. protecting the occupants of the building from the elements, giving them a feeling of safety and comfort. It is important to provide safe foundations for a building but equally important also, to provide a good and appropriate roof above it. Good foundations protect the building against damage from below the ground and a good roof prevents deterioration of the building from the top.

The design of the type of roof for a building should be made after due consideration to its 
structural function of spanning the space and helping to control the climatic conditions within it (Schrenkenbach, 1981; Foster and Greeno, 2007). This is imperative due to the fact that, the choice of certain roof types may not be prudent if the spans are large. For instance, the use of a double pitched roof (with only a $15^{\circ}$ inclination) for a $30 \mathrm{~m}$ span roof would produce a roof more than one storey high at the ridge (about four metres) in addition to a large and costly roof space, which may not be needed. Such large spans with high levels of inclinations also set up serious stresses within the walls of the structure which needs to be taken care of in the design. However, in multi-storey buildings, the spans are usually not great and the roof is, generally, constructed along the structural lines of the floors below. This is usually so since the structural grid in multi-storey structures are not as wide as those that could be conveniently employed in single-storey buildings.

Pitched roofs are commonly employed in building designs in Ghana, especially in the southern and middle portions of the country, where levels of rainfall are relatively high. The pitch roof construction generally relies on triangular frames of sloping rafters tied together with horizontal ceiling joists, usually with a system of struts. There are also different kinds of pitched roofs depending on the requirements of the building and climatic conditions. For instance, there are symmetrical and asymmetrical pitch roofs. There are also the lean-to roof, monopitch as well as butterfly roofs. All these types of pitched roofs are prevalent in Ghana. However, whatever type of roof is employed in a building, it has certain functional requirements of helping to keep out rain, snow, wind and dust. In addition to these, it should prevent excessive heat loss in temperate climates or excessive high gain in tropical climates, while providing stability with durability. It must, also be aesthetically pleasing. This last requirement, of an aesthetically pleasing roof, encouraged the parapet roof construction in Kumasi in the 1970's. Although parapet roof construction has its peculiar func- tions of protecting roofs against violent windstorms, facilitating rain harvesting, etc, these functions, however, did not inform its use in Kumasi in the 1970's, as this paper would show. It was primarily to hide the roof finishing, since there were very limited varieties of roof materials in that particular era. Exposing them to view, in a way, reduced the building's aesthetic appeal.

In addition to the structural function, roofs have certain performance and functional requirements (which are inter-related). These vary according to the type of building and roof form. Some of these requirements are to;

i) Shade the external walls,

ii) Insulate against solar heat penetration,

iii) Shed rainwater quickly and effectively,

iv) Withstand any superimposed loading e.g. wind pressure, weight of snow, rain etc,

v) Durability and freedom from maintenance, and

vi) Aesthetics.

For instance, with (i) above, this could be achieved with wide overhangs as well as sunshading devices for walls facing east and west. This, if well done, would provide a considerable drop in temperature inside the building. For multi-storey structures, other means of shading are used. With (ii), insulation against solar radiation through the roof structure into the building could be reduced in a number of ways; this could be done by the use of a suspended ceiling, with a ventilated space between the two, use of a dense roof covering material or incorporating insulative material between the roof structure and the covering, or painting with special light reflective paints. With (iii), it is perhaps the most important aspect of the performance requirements after (iv). A roof must be so designed that rain or storm water does not stay too long on it as it may induce the ingress of water into the interior spaces of the building, through flooding of roof gutters and by capillary action between the side laps of the roofing sheets. This is the reason why pitched roofs are mostly employed 
in areas where there are excessive rains. Drain pipes and water spouts should be of the required sizes or dimensions to facilitate an effective and quick evacuation of rain water.

The ability to withstand any superimposed loads as stated in (iv) is, perhaps, the most important requirement of a roof. The other requirements stated above, if not properly met, could be tolerated but if the roof collapses due to a heavy layer of snow, strong winds or rain, lives could even be lost. This also explains why pitches of roofs of buildings in countries that have snow are sometimes very steep (about 35 to 40 degrees). This ensures that snow does not pile on them to a point of collapse. It preserves a useful "insulating blanket" of snow during cold seasons, but permits thaw water to run off freely (Foster and Greeno, 2007). Durability as stated in (v) is also important since the roofs cannot be constantly replaced in the life of a building due to deterioration. It must be built to last as long as the building stands, with occasional periods of maintenance. Absolute freedom from maintenance is, however, not possible since every building material has it life span and as such the roof finishing may need to be replaced after a period of time.

Finally, as said earlier, roofs if well designed contribute in a large measure to the beauty of buildings since they are the most exposed part of the structure after the enclosing walls. A well designed building may not be appreciated if the roof looks incongruous with the structure. Roofs could be flat, pitched or curved. However, there are other types of roofs which may be a combination of two or all the three. A flat roof is one where the slope in any plane does not exceed $10^{\circ}$ to the horizontal and a pitched roof has a slope in any place exceeding $10^{\circ}$ to the horizontal (Grundy, 1997). Other writers state that a roof can be "defined as flat when its weather plane is finished at a slope of $1^{\circ}$ to $5^{\circ}$ to the horizontal" (Emmitt and Gorse, 2006). This could be a single or monopitch, double pitch, butterfly, etc. Chudley and Greeno (2005) also define a pitched roof as, "any roof whose angle of slope to the horizontal lies between $10^{\circ}$ and $70^{\circ}$; below this range it would be called a flat roof and above $70^{\circ}$ it would be classified as a wall" (Fig.1). While the pitch is generally determined by the roof covering, the basic form is governed by the load and span.

\section{PARAPET ROOF CONSTRUCTION}

There are basically two forms of parapet walls; one type consists of the external walls of the buildings raised above the level of the roof for the sake of appearance of the building as a whole, while another type are walls which are built as external walls or fascia to concrete roof gutters. The former, most times, acts as abutments to the roof since they usually make direct contact with the edges of the roof, along the slopes, while the latter does not. The former is usually thicker than the latter. This paper would, however, be restricted to the latter.

Parapet walls are exposed, in both cases, to driving rain and are more liable to damage than external walls below eaves level. The top, which is normally exposed to rain, are covered or capped with some dense material to prevent rain from saturating them. In earlier days in some developed countries e.g. the United Kingdom, natural stone, termed coping stone, was commonly used.

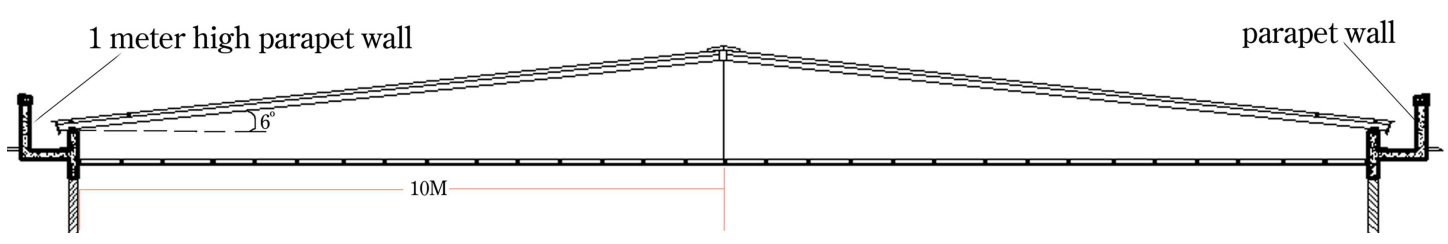

Fig. 1: A low-pitched roof hidden behind a parapet wall 
(Stone is not a major building material in Ghana). They were made to project some $50 \mathrm{~mm}$ or more on each side of the parapet wall, with a semi-circular groove cut in the underside of the over-hang edges (throating) so that water runs off at the extreme drip edges of the coping (Fig. 2 ). The coping is also made to slope so that the weathered top surface slopes towards the roof to minimise staining of the external walls, espe-

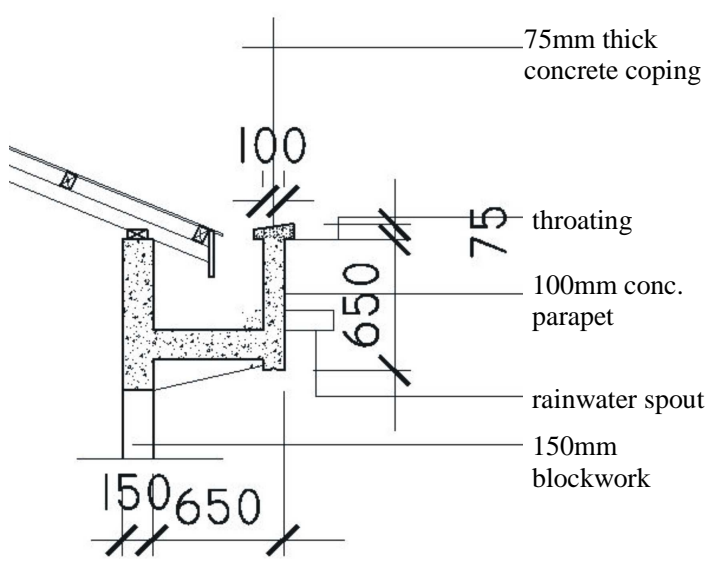

Fig. 2: A typical cantilevered roof gutter with a parapet wall

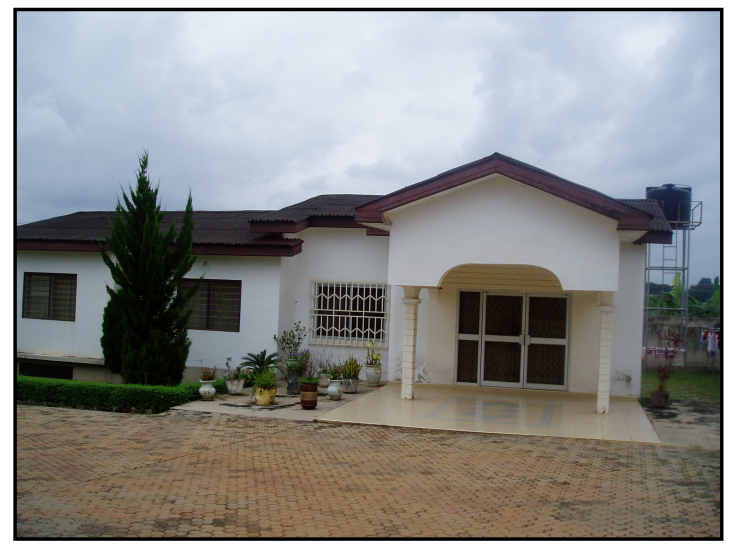

Plate 1 A building without roof parapet walls cially, when they are fair-faced (unplastered brick walls).

A pitched roofs could still have the roof edges or eaves exposed or hidden with a concrete fascia or parapet if it is so required (Plates 1and 2). There are several reasons for the use of parapet walls. A designer could use them to articulate the aesthetics and character of a building. It must not, however, be mistaken here that the sole purpose of roof parapet walls is to hide the roof coverings of buildings. Functionally and technically, it is a practical way of collecting and channelling storm water to specific areas for collection and storage or appropriately discharged through rain gutters, especially, for multi-storey buildings, where rain water falling from great heights, may create serious erosional activities and soil degradation. They could also be employed in areas where strong winds, have the tendency of blowing roofs off buildings.

From the aesthetic perspective, it may be merely a client's own idiosyncrasy or an attempt to hide an inexpensive and not too appealing roof covering from public new. The latter reason is what prevailed in Ghana in the early 1970s, especially in the city of Kumasi. Parapet roof construction became the fashion during that era. It was popularly known in the local parlance as 'Bohyemu'

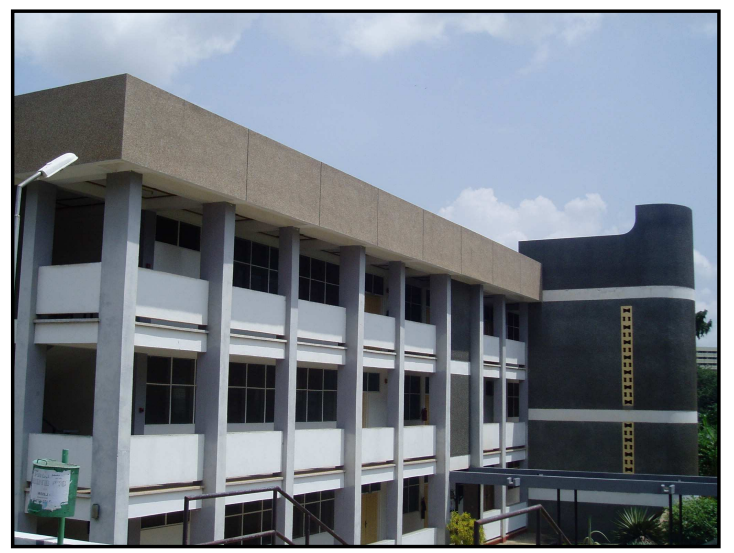

Plate 2: A building with roof parapet walls

126 Journal of Science and Technology, Vol. 28, No. 3, Dec., 2008 
laterally meaning 'construct it inside' or more appropriately, 'hide it inside' (Plate 2).

Before and after the country's independence in 1957, most of the buildings materials were imported. However, after the first coup d'état that toppled the first President of the nation in 1966, importation of these materials become a lot more difficult due to scarce foreign exchange. The variety of roofing materials, which hitherto were available on the Ghanaian market, was limited. People, therefore employed the use of mainly corrugated galvanised, aluminium or asbestos roofing sheets, which were then available. As could be predicted, their aesthetic qualities were not as appealing as some of the current roofing finishings. This, therefore, called for ingenious ways of roofing in order not to expose the roof cover. The parapet roof construction method was then found to be most appropriate.

\section{RESEARCH METHODS}

Due to the problems of leakage of buildings with roof parapet walls, a total of 10 buildings were studied in Kumasi, with three being two-storey buildings. This number of buildings was purposively chosen to represent the following criteria for the study;

i) Those built mostly in the 1970's and showed signs of leakage,

ii) Those with very low-pitched roof (no part of the roof showed above the parapet walls),

iii) Buildings which had had some leakage problems solved by the author, and

iv) Those still under construction.

With reference to (iii), since the problems resolved were not photographically documented at the time of the leakages, sketches of some typical problems encountered have been produced below. Of the 10 buildings studied, three were the storey buildings under construction. One was being conventionally constructed by a contractor, while the others were being constructed by local artisans. One of the two was roofed, but had no ceiling and as such it was easy to visually see the structure of the roof gutters, in relation to the parapet walls. Of the seven single-storey buildings studied, all were built in the early 1970's and had their ceilings in place, as such it was difficult to see the ring beam from within during the field work. The author had personally worked and resolved leakage problems on four of them, while the other three had had no history of roof leakages. Of the four whose problems of leakages were resolved, one had to change its entire roof covering from normal-sized corrugated aluminium sheets to long span roofing sheets. Two of these buildings had extra rain water spouts added to facilitate a quick evacuation of rain water in the roof gutters (Plate 6), while the last one had so acute a problem of leakage in almost all the rooms, that the parapet walls were shortened and constructed with a ring beam to enable a new, and completely redesigned pitched roof, to be built on it (Plate 7).

\section{RESULTS AND DISCUSSION}

This study showed that the several problems identified with parapet roof construction in urban areas, especially in Kumasi have not been structural. The problems were mainly leakages due to;

i) Low -Pitched roofs,

ii) Depth of gutter,

iii) Use of a downstand ring beam,

iv) Employment of block work for the parapet walls, and

v) Lack of maintenance.

\section{Low-Pitched Roof}

It has been already stated that any roof which has an incline of less than $10^{\circ}$ with the horizontal is generally considered as a flat roof and with flat roof construction certain precautionary measures or detailing should be considered in order to avert any leakage. With the 'bohyemu' concept of parapet roof construction in Kumasi, most of the roofs have slopes which usually fall within the $10^{\circ}$ inclination limit of flat roof, thereby making them, technically, flat roofs without the requisite measures to forestall leakage. For example, a building which measures 
$20 \mathrm{~m} \times 20 \mathrm{~m}$ may have a concrete fascia with a height of one metre. The fascias are not usually built higher than that due to structural stability. With reference to Fig. 1, it would be realised that with a maximum height of one metre at the ridge, the ratio of the horizontal distance to the height would be approximately 1:10. This works out to be about $6^{\circ}$, making it technically a flat roof.

The problem that this roof is normally associated with is, basically, that of leakage during rainstorms. Most local artisans are usually baffled by this kind of leakage, since it usually occurs at the overlaps or junctions of the corrugated roofing sheets used. Due to the almost flat nature of the roof, rainwater stays slightly longer on them than it would on a pitched roof, as such water enters through the overlapping sheets by capillary action and drip onto the ceiling of the building into rooms below (Fig. 3).

\section{Depth of Roof Gutter}

Figure 4 shows a detail drawing of a roof gutter, parapet and the eaves of a typical parapet roof. It would be observed that it has everything that would make it function as a roof gutter. However, a critical assessment would reveal certain basic flaws, which may result in a leakage.

A ring beam of about $150 \mathrm{~mm} \times 225 \mathrm{~m}$ supports and anchors the rafters. The concrete slab of the gutter is about $150 \mathrm{~mm}$ thick, supporting a parapet wall of $100 \mathrm{~mm}$. This, therefore, means the depth of the gutter, has been reduced to about $75 \mathrm{~mm}$. With a cement/sand screed finish of

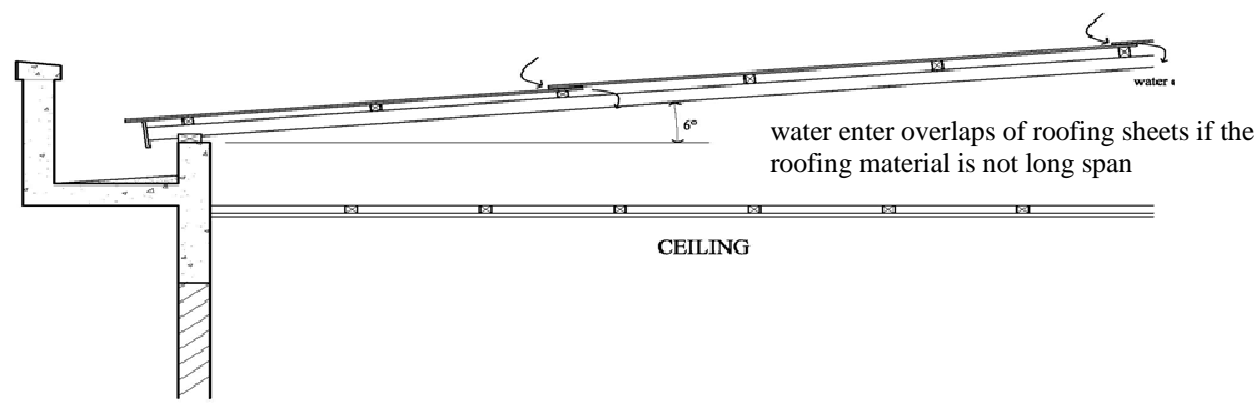

Fig 3: Low-pitched roofing and the risk of leakage through the overlaps of the roof coverings

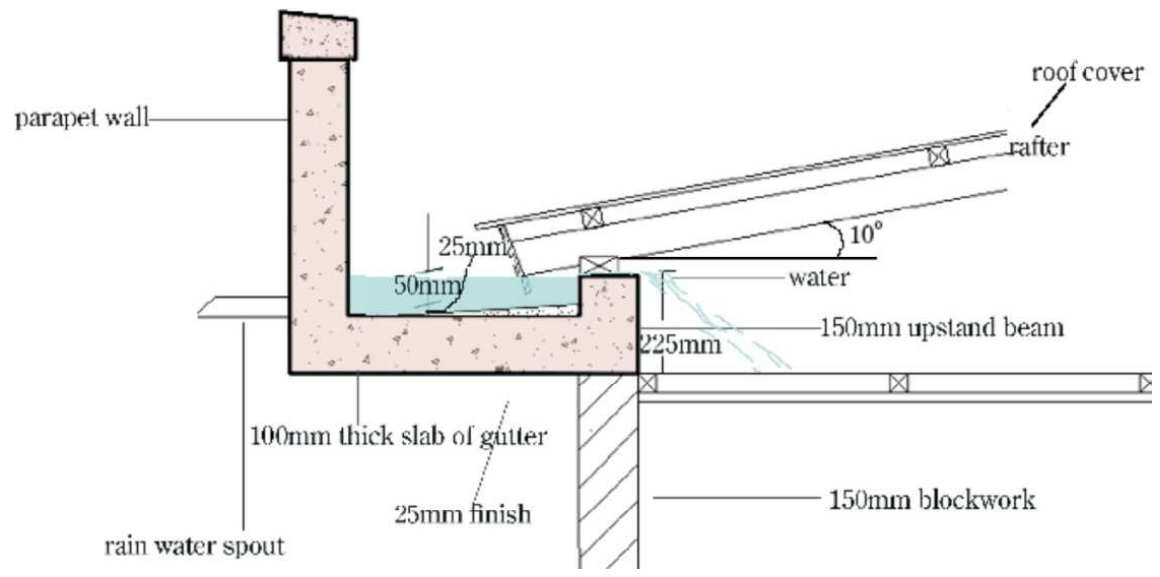

Fig. 4: A reduction in the height of the upstand beam and the risk of water entering the roof space

128 Journal of Science and Technology, Vol. 28, No. 3, Dec., 2008 
about $25 \mathrm{~mm}$ thick laid to fall, it would be further reduced to $50 \mathrm{~mm}$ deep. This therefore means, the critical depth at the beam end of the gutter available for rainwater collection, is only $50 \mathrm{~mm}$. This situation would definitely result in leakage problems during heavy rainstorms when water, collected in the gutter, rises quickly and goes over the edge of the beam (i.e. under the wall plate into the ceiling space). In most of the leaking roofs encountered in practice and during the study, the water does not drip directly onto the ceiling. To the annoyance of the occupants, it drips along the walls, thereby making it difficult to collect the drops in a container. During the study, a landlady indicated that she always leaves the house in the rainy season with pieces of cloth lined along the base of the walls which drip with water, in order to soak the water in case it rains in her absence.

\section{Downstand Ring Beam}

Figure 5 shows that the workmen have wrongly constructed a downstand instead of an upstand ring beam. In this particular instance, the leakage comes about when rainwater slowly seeps through sand/cement screed laid to fall in the gutter itself and then goes through the mortar

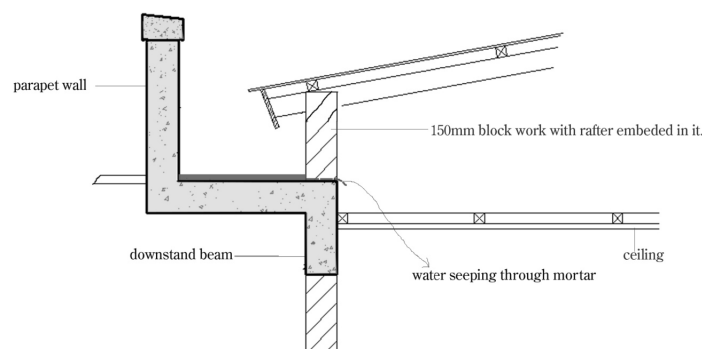

Fig. 5: Parapet Roof with a Downstand beam

joint between the block work and the downstand beam. This type of leakage may take a longer time to manifest if the sand/cement screed is rich, but it would eventually occur.

The use of Block work for the Parapet Wall The fourth problem is two-fold and are, relatively, of little nuisance due to the fact that the leakage occurs outside the building rather than into the interior space. Figure 6 shows a detailed drawing of a parapet wall built entirely of

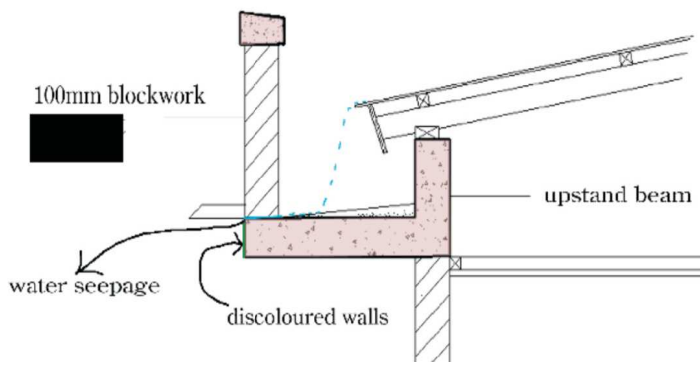

Fig. 6: The use of block work instead of reinforced concrete for a parapet wall

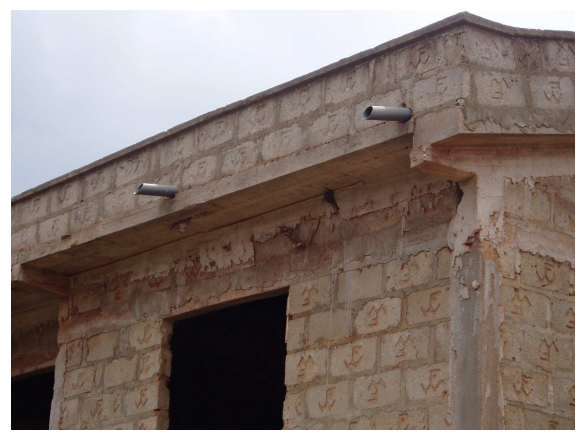

Plate 3: Example of the use of sandcrete blocks in constructing a parapet wall.

$100 \mathrm{~mm}$ thick block work, while Plate 3 shows a picture depicting it as constructed. This practice is usually to help reduce cost of construction, since in this instance, concrete and reinforcement bars are eliminated.

Here the problem is seepage of water between the mortar joint under the parapet of block work and the reinforced concrete base of the gutter. This causes discolouration on the exterior surface (of the lower portion of the façade of the parapet,) and destroys the aesthetic quality of the paintwork, in addition to the manifestation of a thin crack in the plaster, at the junction where the blockwork meets the concrete slab (Plate 4).

The other problem is seepage through the con- 


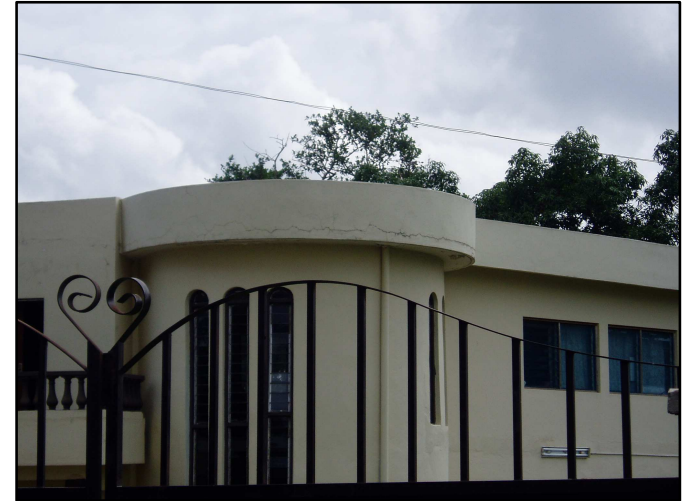

Plate 4: Shows a crack in the cement/sand plaster where the blockwork meets the concrete slab

crete base of the roof gutter when water stays too long on it. This may be due to inadequate falls in the gutter, a poor mix of the sand/cement screed or the concrete itself used in constructing the gutter.

This kind of seepage would rust the reinforcement bars within the concrete and weaken them. It may eventually cause it to collapse but before this happens, discolourations of the soffits of the gutters occur, with the plastering falling off in bits and pieces (Plate 5).

\section{The use of Block work for the Parapet Wall}

This final problem is merely a lack of maintenance. In some cases, leakage of rainwater through the roof into spaces below may not be due to any of the problems above. Everything regarding construction, detailing and specifications might have been done correctly, however due to a poor maintenance culture, a leakage might occur. This leakage may be mainly due to

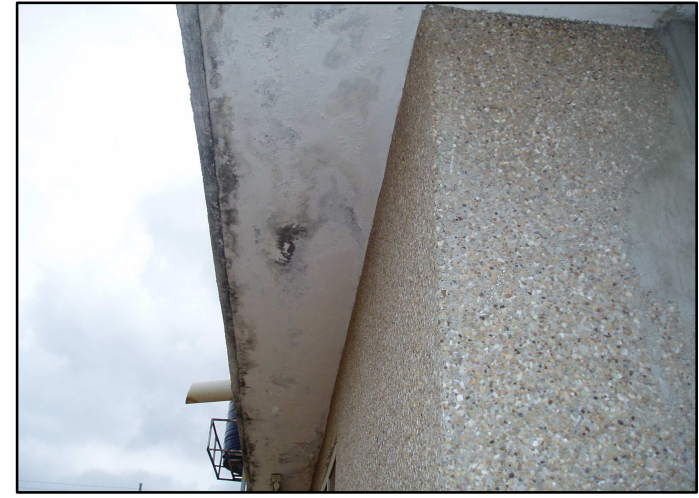

Plate 5: Discolourations due to seepage

rainwater spouts, which have been chocked or blocked by dirt and possibly organic materials such as dead leaves and twigs, which are blown about during rainstorms. During the study it was observed that quite a number of domestic buildings rain water spouts had been blocked by birds' nests. This does not allow rainwater to exit quickly enough and gradually rises till it goes over the ring beam into the roof space.

\section{RECOMMENDED SOLUTIONS}

Some practical solutions have been recommended for these problems:

\section{Low-pitched Roof}

The simplest solution to this problem is to utilise long span corrugated roofing sheets. To achieve this, the distances from the ridge to the eaves are measured and the roof covering cut to the required specification, at the factory. In effect, what is achieved is a jointless roof covering along the whole length of the slope of the roof.

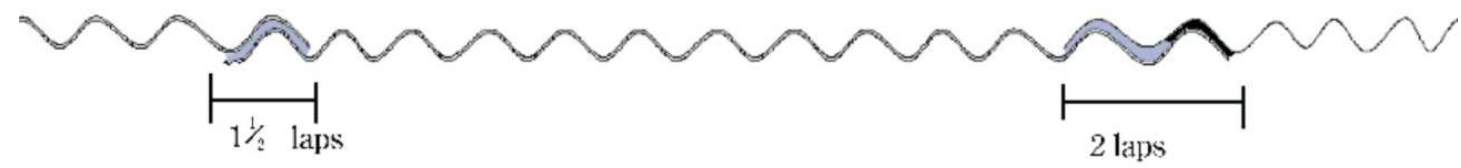

Fig. 7: $1 \frac{1 / 2}{2}$ and 2 corrugations side lap for pitched and long span flat roof coverings in tropical countries, respectively

130 Journal of Science and Technology, Vol. 28, No. 3, Dec., 2008 
The horizontal overlap (side lap) of corrugations of the sheets could also be increased to forestall any capillary action, of storm water in that direction. Usually one and a half corrugations side lap is recommended for corrugated roof coverings built in tropical countries while flat roofs with long spans should have two corrugations side lap (Schrenkenbach and Abankwa, 1981) (Fig. 7).

Another solution one could consider if the client wants a concrete fascia parapet, (but is not too concerned about hiding the roof) is to increase the pitch and make it higher than $10^{\circ}$. This would make the ridge appear above the top of

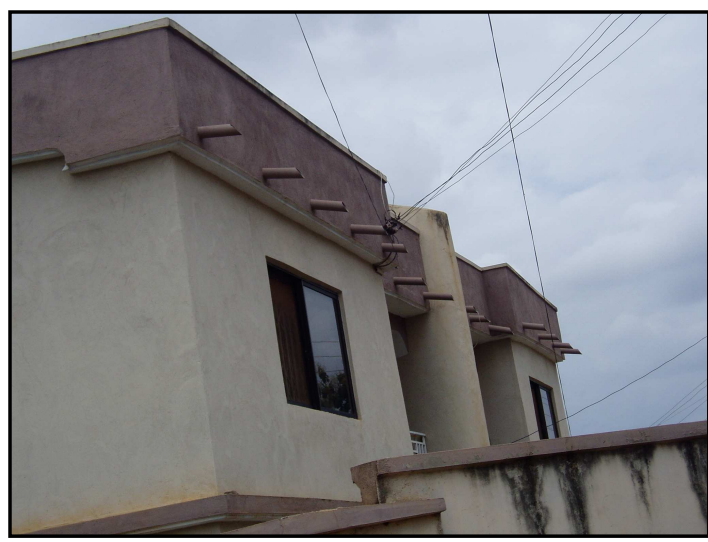

Plate 6: Shows the introduction of extra rain water spouts in the parapet walls of the roof to solve the problem of leakage. the parapet walls but give the roof a good slope to prevent rain water staying longer on it.

\section{Depth of Roof gutter}

With this problem, the easiest solution that could be effected is to introduce extra and/or bigger rainwater spouts to help the quick exit of water from the gutters (Plate 6). Another solution would be to widen the width of the gutter itself, if it is found to be too narrow. That would however, entail greater costs.

However, to forestall any leakage, parapet roof gutters should be designed or constructed such that they are wide and deep enough (at least $400 \mathrm{~mm}$ and $300 \mathrm{~mm}$, respectively). The number of rainwater spouts should also be enough, (depending on the area of the roof) and regularly spaced to help water exit quickly. An innovation that could be used is by redesigning the gutter itself such that the point at which it is connected to the ring beam is thicker than the edge on which the parapet wall sits (Fig. 8).

In effect, the concrete base on which the parapet wall sits is sloped. In this instance, stormwater would exit as fast as is necessary and would not rise to the level of the ring beam, since it could be rightly assumed that before that happens, all the water would have drained off through the provision of an effective system of water spouts.

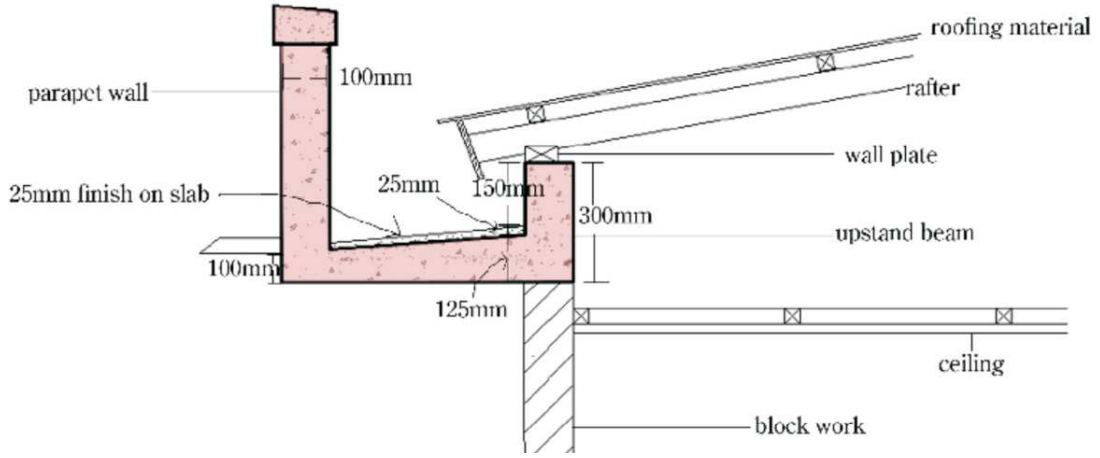

Fig. 8: A wedge-like slab and an increase in the depth of the upstand beam as a solution to leakages 


\section{Downstand Ring Beam}

This problem could also be dealt with by removing the existing sand/cement screed, which has been laid to fall in the gutter, and lay a richer mix of same, (e.g. a mix of 1:3) with a greater slope such that water does not stay near the wall on which the roof members are anchored, with the necessary waterproofing on the surface as required. However, if in the design there is the need for a downstand ring beam due to structural considerations, a concrete upstand of, at least $150 \mathrm{~mm}$ high, could be constructed (on top of the downstand beam) before any block work. This would help contain any water and prevent seepage due to its monolithic nature (Fig 9).

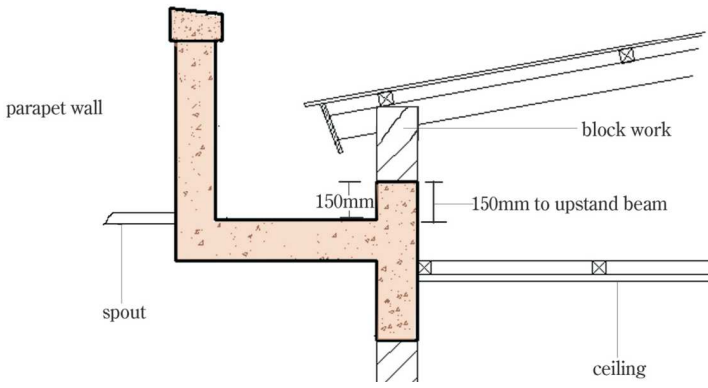

Fig. 9: Use of both an upstand and a downstand beam in a roof gutter.

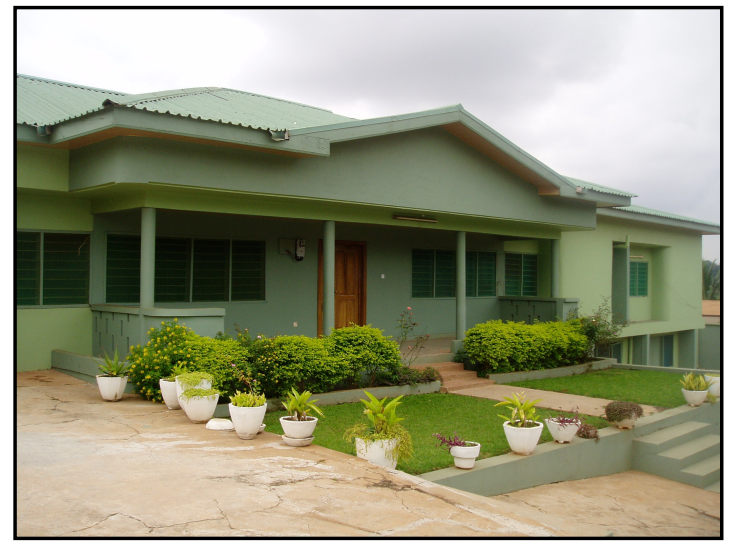

Plate7: A building with a redesigned roof, eliminating the concrete gutter altogether
Plate 7 shows the picture of a building, worked on by the author, which had a similar problem. The problem was so acute due to the poor nature of the detailing, blockwork, and mortar used, that almost all the walls inside, dripped with rainwater during rainstorms. Coupled with this was also the problem of seepage through the overlaps of the roof covering. It was technically a flat roof without long span roof covering. The existing parapet walls were removed and replaced with new (shortened) parapet walls (with a ring beam) and a redesigned pitch roof.

\section{Use of Blockwork for Parapet walls}

The problem could be resolved by constructing a reinforced concrete parapet wall of about 75$100 \mathrm{~mm}$ thick (Fig 9). However, in a bid to cut down cost, block work could still be used as shown earlier above. However, if block work is used, a concrete upstand beam of at least $150 \mathrm{~mm}$

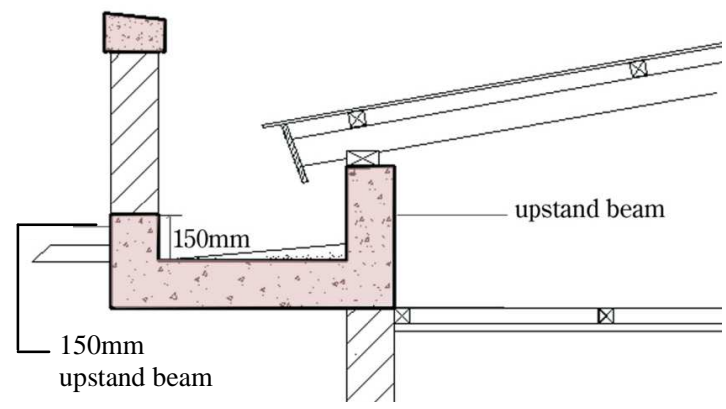

Fig. 10: Use of $150 \mathrm{~mm}$ high concrete upstand before the block work to solve seepage

high should first be constructed on the concrete base of the gutter before the block work is added (Fig. 10). In other advanced countries like United Kingdom and the United States of America, this problem is usually forestalled by the use of a Damp Proof Course and metal flashing at this level (Chudley and Greeno, 2005).

In this particular instance, it would also be advisable to construct a coping of mass concrete on top of the block wall to give it some structural integrity as well as helping to keep the fascia

132 Journal of Science and Technology, Vol. 28, No. 3, Dec., 2008 
clean. As a precautionary measure, all solutions discussed above should have the sand/cement screed finish in the gutters painted over with two coats of flinkote or any other appropriate water proofing material. However, this needs regular maintenance of repainting.

\section{Lack of Maintenance}

The solution to this problem is obvious; clean out the rain water spouts on a regular basis, at least, once a year, before the major raining season. Most times, the water spouts employed in the buildings are $75-100 \mathrm{~mm}$ PVC pipes, inserted, horizontally in the parapet walls, enabling rainwater to fall outwards, away from the building. Over time, they accumulate pieces of debris, especially, leaves which are blown about during the onset of rains. There have been instances where wood shavings, saw dust and mortar, left in the gutter during construction, find their way into these pipes, clogging them with the inevitable consequence of flooding of the gutters and eventual leakage into the interior spaces. Fixing a metal grille over their openings would, exacerbate rather than solve the problem, since they clog up faster with debris than the pipes.

In an attempt to resolve these problems revealed by the study, an accurate assessment needs to be carefully made and considered before any of the recommended solutions is employed. This is essential, since a wrong “diagnosis' could cost the client dearly and dent the reputation of the consultant as well. One thing that one can be sure about is that, if the inside walls of a building where the gutters are, drips with water after rains, then definitely there is a problem with the gutters. If it is a flat roof (roofed without long spans) and leaks from the ceiling but not along the walls, then it could be a side lap problem or a simple problem of nailing down the edges of the side laps since they might have been lifted by windstorms over the years, as usually observed.

One fact that was established during the study is that all the single-storey domestic buildings presently under construction within the suburbs where the study was undertaken were without roof parapet walls. However, if any had a terrace with a flat roof, short parapet walls were employed to restrict, control, and direct storm water into rain water spouts. This somewhat, confirms the fact that people now felt comfortable exposing their roofs due to the plethora of roof finishings presently available. Others explained that with the present high cost of iron rods, it made economic sense to avoid the use of concrete roof gutters with the parapet walls.

This problem with roofs also brings to mind the problem of roof anchorage to the superstructure in buildings. In a research conducted in Kumasi, it was realised that there are major problems with how local artisans anchor roofs to the superstructure, which has led to a number of houses having their roofs ripped off during rainstorms (Afram and Amos-Abanyie, 2008). Designers must therefore, not only consider the aesthetics of a building but must also pay extra attention to those aspects of the structure which would enable it stand the test of time.

\section{CONCLUSION}

The study dealt with parapet roof construction which became fashionable in the 1970's in Kumasi due to the limited variety of roof finishing. It brought in its wake problems of leakages due to poor construction and detailing, mostly associated with local artisanal construction. After purposively selecting a number of buildings within the categories of the 1970 era, multistoreys and mode of construction (i.e. artisanal or conventional), the study revealed a number of leakage problems associated with this type of roof, namely, leakages due to; low-pitched roof, insufficient depth of roof gutter, use of downstand ring beam and blockwork for the parapet walls, as well as the lack of maintenance.

From the results of this study, it could be concluded that, greater care must be exercised in the design, detailing, construction and supervision of parapet roofs. Most of the problems of leak- 
age were as a result of poor detailing and construction, in addition to inadequate technical know-how and ignorance by local artisans who were usually commissioned to build them. Qualified technocrats in the building profession in our part of the country should design in greater detail and with a little more 'margin of safety', coupled with intensive supervision and instruction of construction works, especially involving parapet roofs. Proper supervision of these artisans would, in the long run, help train these artisans with the public at large benefiting from their expertise, since they would invariably be commissioned to construct houses for them. Building technicians, who may be consulted to resolve some of these problems revealed by the study, must carefully carry out a diligent and accurate assessment of the problem before any of the recommended solutions is employed.

The public should also exercise due diligence when commissioning these artisans to build for them. They should visit and inspect some of these buildings that have been built by them in order to ascertain how well they have performed over the years, in terms of leakages. This could be of immense help in averting most of the problems revealed by this study. It must, however, be emphasised here that the solutions prescribed above are not the ultimate to the problems, but the principles governing them remain the same and upon these, other appropriate and perhaps better ones, could be developed.

\section{REFERENCES}

Afram, S.O. and Amos-Abanyie, S. (2008). Structural Failures of Artisanal-built Roofs durings Rainstorms, in Ghana: Some Common Causes. Journal of Building and Road Research Institute, (BRRI) KNUST. (In Press).

Chudley, R. and Greeno, R. (2005). Construction Technology, Third Edition. Pearson Education Ltd, UK. pp. 218-219.

Emmitt, S. and Gorse, C. (2006). Barry's Introduction to Construction of Buildings. Blackwell Publishing Ltd, UK. pp 301.

Foster, J.S. and Greeno, R. (2007). Structure and Fabric, Part 1, ( $7^{\text {th }}$ Edition). Mitchell's Series. Pearson Education Ltd, UK. pp 138140.

Schrekenbach, H. and Abankwa, J. (1981). Construction Technology for A Tropical Developing Country. Deutsche Gesellschaft, Germany. pp 153. 